\title{
Research on Transmission of Chinese Ancient Literature based on Digital Film and TV Media
}

\author{
Wenjie $\mathrm{Li}^{1}$, a \\ ${ }^{1}$ Teacher's College, Beihua University, Jilin, China \\ a254519852@qq.com
}

Keywords: Chinese culture; digital film and TV media; Chinese ancient literature; transmission Abstract. According to t promote and develop Chinese culture, in this paper, the significant and function of the digital film and TV media to transmission of Chinese ancient literature was analyzed in many aspects. At last, the research conclusions of carry forward Chinese culture were prospected.

\section{Introduction}

With the depth of electronic information, view the era into life, video and other digital media is omnipresent, digital video art is one of today's mainstream media, it has been swept into a visual image of the brain of the era, digital media and digital images do its utmost to provide a way for people to meet and desires. Young and vibrant film and television art, and ancient Chinese literature, in a past century has been showing in artistic practice blending gesture.

In this cultural environment, in which rapid social and cultural transformation process, the ancient Chinese literature are gradually groping to find a new form of expression, and gradually adapt to and use of this media environment. In order to expand communication channels, more and more Chinese Ancient Literature "invited" to participate in the trend of the Creation and adapted into film and television works were to go, visualization has become a new trend spread of ancient literature, new areas, literature and film phase Fusion, Film lifts Literature, propagation space complementary positive interaction become mainstream in the future, the literature is infinite expansion. Image for the public has become accustomed to, in terms of the spread of literature, become more efficient, to accept more pleasant. Therefore, a multi-dimensional, multi-mode, high-participatory art appreciation in the way of people's lives gradually becomes an indispensable means.

Digital video of the classical literature, not only represents the idea of changing people's lives, behavior gradually undergoing a series of changes to the final refraction ideas and way of reading are becoming digital, Visualization. From this perspective, the significance of communication channels of classical literature has been far greater than the attention to the text itself. Interactive digital video era classical literature and film has become an irreversible trend.

Back in history, the era of total propagation characteristics of the text, in the heart of the communication field is spoken and written language, is something that falls on paper. At first, people understand the external messages are through word of mouth, for distant world, able to get bits and pieces of news will certainly be after the event had occurred before. Satiric hindrance spread the message of this era has been an insurmountable obstacle.

\section{Information technology}

In the era of digital television, electronic technology, information technology, space technology to break the limitations of distance, language and writing at the end of culture, civilization Spread dominate, from the image on the success or failure of the times to come. Digital video media, in recent years, has gradually established its own dominance in the mode of discourse and mode of transmission. Ancient literature constituted by the text, the text written as its creation, the main mode of transmission, thereby becoming the only way to read literature literary acceptance, there is no "communication hegemony," However, in the era of digital television, all the knowledge, the image has an intuitive way 
motion presented. Vision, even if it is not watched intently, dissemination of results still outstanding. This is why digital video media soon as he was born to immediately form their own reasons hegemony.

In today's digital imaging technology, can calm down and read the text of readers less and less, and visual sensory stimulation and pleasure in the divertissement not entirely under the control of the heart, ruminant text in the text itself, a great digital video media dependency of literary texts Italy. In the literature written by the text, the text read transfer to the imaging performance of the process, the traditional form of text perception becomes a direct effect on the human eye and the senses by imaging the brain, which is very intuitive way of expression so that the audience can quickly and Television image Personal perception of interactive, thus accelerating the process of literary text understanding and acceptance of the audience. The promotion of literature and digital video interactive media are on the one hand to promote the dissemination of literature in the field of infinite expansion. After the TV series "Three Kingdoms", "Dream of Red Mansions" and broadcast, so a large part of the television audience is how to produce original curiosity, instead refocus on the original, attention author, that digital video led to the relevant literature and its surrounding Literary works, "Resurrection", which proves in this film and literature interactive process, the nurturing role of film and television on Literature.

In the era of digital television, literature, whether active or do nothing, she began joint television; and film it, absorb nutrients from the literature where, at the same time, the formation of the "product" constitutes a contemporary popular culture, therefore, ancient literature and digital film culture mutual actuation, inseparable. Literary works are able to integrate digital media era in video communication process literary works, will own visual language, visual reception mode combined with the most needs of the masses, the integration of the dual characteristics of ancient literature digital video and digital art, on the one hand to give Ancient Literature nourish, splendid ancient civilization to modern means of communication to provide a steady stream of nutrients, on the one hand can enhance the characteristics of the times of ancient literature and synchronization. Meanwhile interactive view of this literature and film forms of communication continue to develop and grow, but also to the broader public acceptance groups, images of ancient literary texts accepted now and in the future play a role in fueling.

World of written language for most people is undoubtedly a transformation blurred, strange multipart maze. Text era to be grasped by means of text symbols to show things, must have a certain perception of certain words, understanding, organization and the ability to choose, which requires the recipient to have a certain level of knowledge, culture and subjective Deep emotional constraints, and this will inevitably lead to stratification between various sectors in cultural interest, on the cognitive level, ie short text communications services object must be literate intellectuals, had been spread on the premise limitations and constraints conditions. Even in ancient times people far beyond the level of knowledge in modern society, for Chinese Ancient Literature - particularly the use of classical antiquity written reading literary classics, it is still a challenge for the general public sort of. The objective existence of professional knowledge barriers, making a considerable part of the population of Chinese Ancient Literature at arm's length. The audiovisual communication provided specific, image, direct, audible visible image, it is the human way of life in the outside world and a similar perception, no special study will be able to easily access information and digital video media and the objective world true nature intrinsically linked, fully immersive nature to meet the audience immersion, current sense and a sense of participation. Digital media image gradually allow people to accept without hesitation, the image for the public's attention has inherent advantages, because $80 \%$ of the information by the human visual acceptance.

Some of the characteristics of visual language in its present age and cultural level to get through the barrier, there is "a picture is worth a thousand words" effect, in a way, which is impossible in the form of written reports. Undoubtedly, the scope and speed are audiovisual dissemination of information faster and wider than the text. That is, the images of the obvious symbols of figurative, unlike text symbols require specific decoding process, and it is the intellectual talent of this process can be achieved. Thus, the private sector in the past and even ideology eventually unable to conquer, with the 
help of the mass audiovisual culture is overcome in one fell swoop it, and its unique charm affecting people's daily life and way of thinking.

But it needs to be emphasized that the film and television work is not equivalent to literature, according to the ancient Chinese literary classics adapted for film and television works naturally not equivalent to the ancient literary classics themselves. Television images to people is direct sensory stimulation, is figurative, but audiences established by the original film image and literary contact is indirect. Also, literary texts give the reader room for imagination in the reading process in the film of the process of being dispelled. However, the ancient literary works by film of this new form of communication, found a way to break the threshold of propagation, fast, widespread dissemination of literature is the meaning of the film lies.

Popular Culture on behalf of the community gradually becomes the mainstream, cultural ideology of consumption era has gradually become the dominant ideology, the rise of digital television and popular culture has become the overall characteristics of the times. A huge impact on the mass consumer culture and ancient literature caused deconstruction change existing form of ancient literary texts, and then the mode of transmission has changed. On the one hand there is the ancient literature classics in favor of the popularity of return, on the one hand yet classical, sacred history and mystery of ancient literature also cause be removed, which means that the depth of ancient literature in the classical sense of digestion, which means the spirit of ancient classical literature Meaning of being shallow. Cultural context, the value of ancient literature and all other specifications are as interested in the mass consumer culture while undergoing change, public acceptance of ancient literature classics mentality, accepted goals and expectations vision etc changed nature. Digital video media for the dissemination of the body of contemporary society, the rise of image culture also reshaping the ancient literature.

\section{Significance}

First of all, this thesis writing capable of building China Ancient Literature Theory areas play a role. A study of ancient literary theory based on the digital video viewing, though not on the basis of a new academic space, but for now, most fruitful research often focuses on both ends, namely research and media studies conscious digital video of ancient literature, They did not form a unique, specialized discourse mechanisms. Even the definition of "digital film" of the era also failed to keep up with the beat. Therefore, to strengthen theoretical study of ancient literature in the digital video media environment is already pressing the.

Secondly, this study may expand certain extent on research methods. Methods represent the degree of development of the discipline. As traditional Chinese art of poetry reviews the way intuition sentiment - has gradually decline, because it requires researchers also have creative artist or writer accomplishment, and this is precisely not obtained through academic training effective. So combine communication theory can open up, or change direction exegesis called textual criticism extends beyond after. Therefore, strengthening the methodology of this discipline has become one of the important figures of ancient literature of today's researchers.

Third, this study helps to promote horizontal contrast interdisciplinary research. Most of the research is the study of ancient literature for propagation in a unilateral individual level phenomenon, the use of subjective judgment assumes final empirical research methods to investigate evidence of specific methods. Therefore, to analyze propagation phenomena in ancient literature can easily be asserted, assuming other factors, the lack of objectivity of the foundation. In fact, on a certain level of single longitudinal research is not enough, because the spread of a long history of ancient literature, spread complex situation, many spread levels, and therefore various disciplines unconnected way in contemporary academic field of vision is not feasible. Therefore, to promote cross, comparative interdisciplinary research, from different disciplines, media, psychology, consumer culturalism, aesthetics, art and so on their own vantage point, combined with a multi-level, each side, multi-angle approach the starting point, only there may come a comprehensive, objective, scientific achievements and values to contemporary. 


\section{Summary}

Digital video research on ancient literature, it can provide a better theoretical basis and practical study of the practice. A study of ancient literature spread most easily caught in narcissistic limitations, the highbrow often become an excuse for its own closed. Ancient Literature because of its content and form of all with the presence of a strong sense of history, society already has a huge and ancient literature germinal different place, therefore, such studies tend to have a natural weakness in practical terms, because a lot of people will criticize the study of ancient literature and our real life and there is no direct contact, easily fall into the history book bags out of the pile. But in fact, through the ancient literature of digital video media phenomenon of analysis, we can find ancient literature and revitalize the status quo, can better understand the root of our nation can be more deeply the nation's collective consciousness and collective unconsciousness Expand, thus pointing to the moment, to point to our secular society. From a pragmatic point of view, the current cultural policy, cultural systems of innovation, formulation, correction need basis and criteria, then the classical literature of classical, literary, historical initiative spanning all have an irreplaceable role. Confucius said: "Reviewing the Old, can serve as a teacher," classical literature combined with digital video media, not only to make classical literature and revitalize itself, but also the future of revival of literature, the spread of the situation to make a certain degree of forecast. Therefore, in the digital video communication research of ancient literature in the media consciously tend to "fashion", the most inescapable domain "moment" comparative studies, to better highlight the academic value of ancient literature research dissemination, academic pursuit of academic heights.

\section{References}

[1] Zhao Yali. Interaction of current literature and film. Qinzhou College .2010, 1. 30-33.

[2] Wenjun hung image of charm and television modeling under visual culture background research. Film Literature .2010,3. 31-34.

[3] To Huai Lin and video space visually pleasing - Also on Television and Literature different character features contemporary literary and aesthetic function .2010,5 24-28..

[4] Jane Min. To accept the spread of television and literature. Wuhan University (Liberal Arts Edition) .2009,2. 213-316.

[5] . Zhang red and literary counterparts: from literature to film narrative narrative Gansu Social Sciences .2003,6 458-461.

[6] Solution Xi Zhang. Film narrative art of public emotion models. Picture Arts .1998,3. 45-49.

[7] Li Li, Hui burning high. Chinese traditional cultural resources and the TV drama art. Modern Media .2010,7. 123-125.

[8] Ai • Fez Montpellier. The relationship between literature and cinema world cinema .1984,2 56-59.

[9] Orr European and American literary adaptation of the film. 12-15 .1999,3 world cinema. 